\title{
Solução de um problema de transporte de contaminante em corpos hídricos utilizando o método dos volumes finitos
}

\section{Solution of a contaminant transport problem in water bodies using the finite volume method}

Anna Luisa Soares Castro Coimbra1 ${ }^{1}$, Wagner Rambaldi Telles², Fábio Freitas Ferreira $^{3}$, Jader Lugon Junior ${ }^{4}$

\section{RESUMO}

Sendo a água um dos recursos fundamentais para a qualidade de vida e existência das futuras gerações, a preservação ambiental torna-se dever de todo ser humano. Entretanto, é notável a existência de algum tipo de poluição na maioria dos rios no Brasil e, diante de situações como essa no mundo todo, a própria Organização das Nações Unidas enfatiza a importância de se ter um exímio controle sobre a qualidade desses corpos hídrios. Assim, o presente trabalho buscou simular um cenário de poluição acidental no curso de água, com o intuito de formular e implementar um modelo matemático, em que o seu resultado numérico se aproxime do problema real acerca do transporte de contaminantes em rios, com dados experimentais obtidos em um trabalho de campo realizado no rio São Pedro que está situado na região serrana do Estado do Rio de Janeiro. Para a modelagem, foi usado um modelo matemático unidimensional resolvido através do Método dos Volumes Finitos, com as formulações explícita e implícita, o qual tem como base as integrais múltiplas e as séries de Taylor. Foi observado que os resultados numéricos se aproximam do problema real relacionado ao transporte de contaminantes em rios.

Palavras-chave: Poluição Hídrica, Modelo Matemático, Método dos Volumes Finitos.

\section{ABSTRACT}

As water is one of the fundamental resources for the quality of life and existence of future generations, environmental preservation becomes the duty of every human being. However, the existence of some type of pollution in most rivers in Brazil is noteworthy and, faced with situations like this worldwide, the United Nations itself emphasizes the importance of having an excellent control over the quality of these water bodies. Thus, the present work sought to simulate a scenario of accidental pollution in the watercourse, in order to formulate and implement a mathematical model, in which its numerical result approaches the real problem about the transport of contaminants in rivers, with data experimental results obtained in fieldwork carried out on the São Pedro River, which is located in the mountainous region of the State of Rio de Janeiro. For the modeling, we used a one-dimensional mathematical model solved using the Finite Volume Method, with the explicit and implicit formulations, which are based on multiple integrals and Taylor series. The numerical results were observed to be close to the real problem related to the transport of contaminants in rivers.

Keywords: Water Pollution, Mathematical Model, Finite Volume Method.
Graduada em Matemática

INFES - Universidade Federal

Fluminense

anna luisa@id.uff.br

2 Doutorado em Modelagem Computacional - INFES

Universidade Federal Fluminense - wtelles@id.uff.br.

Doutorado em Modelagem Computacional - Departamento de Ciências da Natureza Instituto de Humanidade e Saúde - Universidade Federal Fluminense

fabiofreitasferreira@id.uff.br.

Doutorado em Modelagem Computacional - Instituto Federal Fluminense - Macaé jlugonjr@gmail.com. 


\section{INTRODUÇAOO}

Água, um dos recursos essenciais para a existência do ser humano e outros seres vivos, é ela que garante a permanência do homem na terra, bem como sua evolução. Segundo Bacci (2008), nosso planeta não teria se transformado em ambiente apropriado para a vida sem a água.

Desde a sua origem, os elementos hidrogênio e oxigênio se combinaram para dar origem ao elemento-chave da existência da vida. Isso se justifica ao passo que o ser humano tem seu primeiro contato com água ainda no útero de sua mãe, envolto em água, o feto se desenvolve até está preparado para nascer. Na filosofia, Tales de Mileto acreditava que a origem de todas as coisas estava no elemento água: quando densa, transformaria-se em terra; quando aquecida, viraria vapor que, ao se resfriar, retornaria ao estado líquido, garantindo assim a continuidade do ciclo. Nesse eterno movimento, aos poucos, novas formas de vida e evolução iriam se desenvolvendo, originando todas as coisas existentes.

A água sempre foi motivo de indagação e veneração em culturas antigas. A água sempre esteve presente na história humana, habitando as regiões costeiras, margens dos rios e mares, as civilizações construíram seus impérios, portos, pontes, lavaram seus corpos, pescaram e beberam suas águas. Mesmo quando há escassez de água, está ainda impulsiona a história gerando conflitos entre civilizações. No entanto ao longo dos anos, essa relação de "deusa" perante ao homem foi modificada, passando de item essencial para existência humana e das demais espécies, para recurso a ser usado, cada vez mais, de maneira indiscriminada, sem avaliar as consequências ambientais em relação à quantidade e qualidade da água.

Considerando que $97 \%$ da água do mundo é salgada, sendo apenas 3\% água potável, ou seja, própria para consumo e, desse percentual, apenas 29\% se encontra acessível, já que o resto está localizado nas calotas polares, a preservação ambiental torna-se dever de todo ser humano, o que impulsionou a Organização das Nações Unidas (ONU) a criar em 2004 o Dia Mundial da Água - 22 de março.

Tomando como princípio que a demanda de água no Brasil (vazão de retirada), é de $1.592 \mathrm{~m}^{3} / \mathrm{s}$, sendo que cerca de $53 \%$ deste total $\left(841 \mathrm{~m}^{3} / \mathrm{s}\right)$ são consumidos, não retornando às bacias hidrográficas (ANA, 2005), sua preservação é dever de todos, previsto, inclusive, na Constituição de 1988 Art. 225 - defendê-la e preservá-la para as presentes e futuras gerações. Porém, atualmente se vive em um dos piores momentos possíveis relacionado ao conceito de poluição hídrica, em especial, dos rios, uma que o 
cenário é preocupante devido ao fato dessa poluição ser uma das causadoras da escassez de água potável (Coimbra, 2019).

Cabe ressaltar ainda, que boa parte da água potável proveniente dos rios sofre constante ameaça de poluição, devido à expansão urbana, aliada ao desenvolvimento da indústria e das atividades agrícolas (ONU, 2010), o que levou o Conselho Nacional do Meio Ambiente (CONAMA), por meio das leis $N^{\circ} 430$ e $N^{\circ} 467$, reconhecer a importância de estabelecer critérios e procedimentos para uso de produtos nos corpos hídricos, bem como seu monitoramento para se determinar o nível de impurezas da água em decorrência do lançamento desse poluente. Mas, na prática é muito diferente, visto que o monitoramento e avaliação pelos órgãos responsáveis acabam acarretando problemas financeiros e logísticos, já que se necessita de material específico e mão de obra qualificada para o trabalho, tornando assim o processo caro.

Nesse contexto, torna-se essencial a utilização de modelos matemáticos, e consequente solução numérica envolvendo algoritmos computacionais para simular o transporte e dispersão de poluentes em cursos d'águas naturais, uma vez que estes podem contribuir para o processo de tomada de decisões, possibilitando a geração de diferentes cenários realísticos sem a necessidade de vários trabalhos de campo para essa finalidade, agregando um melhor custo/benefício no que tange a análise desse tipo de problema.

Para a modelagem do presente trabalho, foi adotado um modelo matemático unidimensional devido à geometria da área de estudos, resolvido utilizando o Método dos Volumes Finitos, com as formulações explícita, a qual é condicionalmente estável, e a formulação implícita, que é incondicionalmente estável.

\section{MATERIAIS E METODOS}

\subsection{ESTUDO DE CASO}

Quando um poluente atinge um corpo hídrico, o mesmo sofre alterações devido às características biológicas, físicas e químicas existentes na natureza, logo, é importante ter conhecimento da área de estudo. Nesse sentido, nessa seção é apresentada uma breve descrição da região de interesse.

\subsection{1. Área de Estudo - Rio São Pedro}

A área de estudo para a qual se aplicou a simulação analisada neste trabalho está situada na região serrana do Estado do Rio de Janeiro, dentro da bacia hidrográfica do rio 
Macaé, a qual possui uma área de drenagem de aproximadamente $1.765 \mathrm{~km}^{2}$ e engloba praticamente toda a área dos limites territoriais do município de Macaé, onde se localiza sua foz.

Em particular, o rio São Pedro, região escolhida para a realização do experimento, está situada em São Pedro da Serra, 7ํㅡㄹ Distrito de Nova Friburgo (RJ), local que foi afetado por um rápido processo de transformação espacial, social e econômica, com fortes impactos ambientais (Lima Verde, 2005).

A região tem como característica uma pequena profundidade e margens repletas de rochas. Além de conter trechos sinuosos e grande biodiversidade, tem como principais atividades econômicas a agricultura familiar e o turismo, dado que a área engloba atrativos como as cachoeiras e a mata, possibilitando a prática de trilhas. Tais fatores levaram a criação da Área de Proteção Ambiental (APA) de Macaé de Cima.

Sendo o rio São Pedro afluente da bacia do rio Macaé, que tem importância econômica inquestionável para o país, justificada pelo abastecimento de toda a área próxima ao rio, assim como a exploração de petróleo e gás natural na região oceânica, torna-se evidente a necessidade de uma melhor avaliação desse corpo hídrico, visto que, segundo Freitas (2015), a qualidade e a quantidade de água que chega à foz do rio Macaé depende do que está acontecendo nas áreas mais altas da bacia. Todos os impactos ambientais que o rio sofrer ao longo do seu curso serão refletidos, de alguma forma, em sua foz, situada em Macaé.

\subsubsection{Descrição do Experimento}

Os dados experimentais utilizados nesse trabalho, tem como base o experimento realizado e descrito por Sousa (2009), o qual ocorreu no dia 26 de janeiro de 2009, com início às 10:50:28 $h$ e participação de 5 pessoas, onde buscou-se simular um cenário de poluição acidental no curso de água em questão. Para isso, foi utilizada uma solução de cloreto de sódio $(\mathrm{NaCl})$ como traçador. Se comparado com outros traçadores, o $\mathrm{NaCl}$ apresenta vantagens como, por exemplo, solubilidade em água, presença natural quase nula, não possui efeitos nocivos ao impacto ambiental, facilidade de armazenamento ou de quantificação e também um custo muito baixo. As medições foram feitas em um trecho do rio localizado na saída da vila de São Pedro da Serra, em frente à estrada do cemitério (22 19.155S, 42 19.897W). Na Figura 1 é apresentada a vista parcial do trecho de interesse do rio São Pedro. 


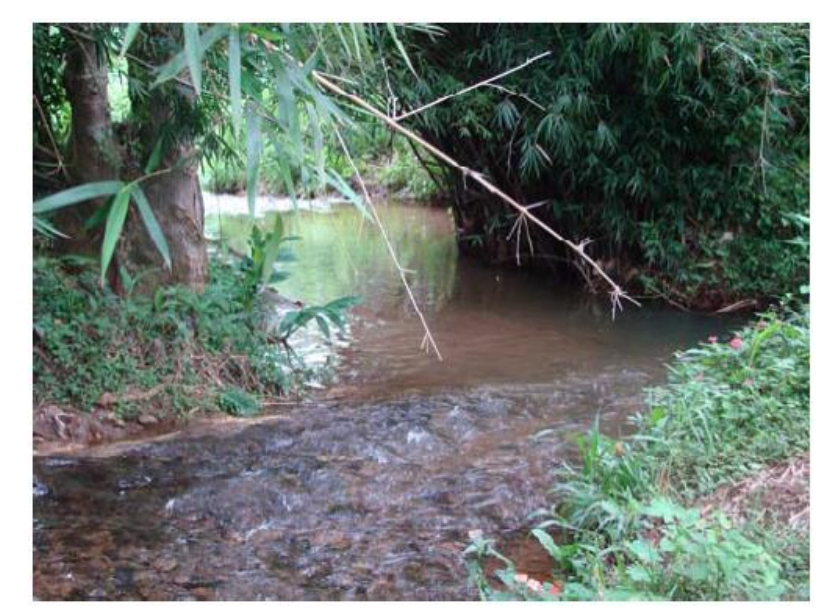

Figura 1. Vista parcial do trecho do rio São Pedro.

Fonte: Sousa, 2009.

Para a preparação da solução salina, foram utilizados $2000 \mathrm{~g}$ de cloreto de sódio, diluídos em aproximadamente $15 l$ de água em um balde, os quais foram liberados instantaneamente em um ponto da seção de injeção, sobre a linha de corrente central do escoamento. A primeira seção foi escolhida a $50 m$ do ponto de injeção e, a segunda, a 100 $m$. Foram colhidas amostras de $200 \mathrm{ml}$ da água a cada $15 \mathrm{~s}$, totalizando 60 amostras, as quais, posteriormente, foram analisadas em laboratório. Na Tabela 1 são mostradas as configurações do rio.

Tabela 1. Características do rio no ponto de lançamento do traçador.

\begin{tabular}{|c|c|}
\hline PARÂMETROS & VALORES \\
\hline Vazão $(Q=U A)$ & $0,43 \mathrm{~m}^{3} / \mathrm{s}$ \\
\hline Área $(A)$ & $1,05 \mathrm{~m}^{2}$ \\
\hline Largura $(B)$ & $2,40 \mathrm{~m}$ \\
\hline Profundidade $(H=A / B)$ & $0,43 \mathrm{~m}$ \\
\hline Velocidade $(U)$ & $0,41 \mathrm{~m} / \mathrm{s}$ \\
\hline Declividade $(S)$ & $0,03 \mathrm{~m} / \mathrm{m}$ \\
\hline Concentração inicial $\left(C_{0}\right)$ & $15,50 \mathrm{mg} / \mathrm{L}$ \\
\hline
\end{tabular}

\subsection{MODELAGEM MATEMÁTICA E SOLUÇÃO DO PROBLEMA PROPOSTO}

O modelo matemático para o problema proposto neste trabalho leva em consideração o fato de o trecho do rio estudado ser suficientemente estreito e raso, fazendo com que as variações nas direções transversal e vertical sejam desprezíveis em relação às variações 
longitudinais. Logo, um modelo unidimensional que considera apenas as variações na referida direção, sendo expresso pela Equação de Advecção-Dispersão, Eq. (1), que descreve o comportamento de um constituinte em relação ao seu deslocamento e sua dispersão ao longo do rio, com condições inicial e de contorno, descritas pelas Eq. (2a) e (2b), respectivamente:

- Equação de Advecção-Dispersão:

$$
\frac{\partial C}{\partial t}+U \frac{\partial C}{\partial x}=E_{L} \frac{\partial^{2} C}{\partial x^{2}}, \quad-\infty<x<\infty, t>0
$$

- Condições inicial e de contorno:

$$
\begin{aligned}
& C(x, 0)=C_{0}+\frac{M}{A} \delta(x),-\infty<x<\infty \\
& C( \pm \infty, t)=C_{0}, \quad t>0
\end{aligned}
$$

onde $C$ é a concentração $(m g / l)$, t é a variável temporal $(s), x$ é a variável espacial $(m), U$ é a velocidade no sentido longitudinal do escoamento $(\mathrm{m} / \mathrm{s}), E_{L}$ é o coeficiente de dispersão longitudinal $\left(\mathrm{m}^{2} / \mathrm{s}\right), M$ é a massa do constituinte $(\mathrm{mg}), A$ é a área da seção transversal do rio $\left(m^{2}\right)$ e $\delta(x)$ é a função Delta de Dirac.

A solução analítica para o modelo matemático descrito na Eq. (1), com condições de contorno e inicial, dadas pelas Eq. (2a) e (2b), é dada pela Eq. (3) (Sousa, 2009):

$$
C(x, t)=C_{0}+\frac{M}{A \sqrt{4 \pi E_{L} t}} \exp \left(\frac{(x-U t)^{2}}{4 E_{L} t}\right),-\infty<x<\infty, t>0
$$

Para a resolução numérica da Eq. (3) foi aplicado o Método dos Volumes Finitos, o qual utiliza a forma integral da equação para obter sua aproximação, dando origem às formulações explícita e implícita, o qual é descrito na próxima seção.

\subsubsection{Método dos Volumes Finitos}

Para o trecho do rio São Pedro analisado neste trabalho foi realizada a discretização do domínio unidimensional, dando origem às malhas espaciais, para que possa ser aplicado o Método dos Volumes Finitos. Na Figura 2 é mostrada uma representação ilustrativa da malha espacial para o Método dos Volumes Finitos, onde as letras $W$ e $E$ indicam as 
direções Oeste e Leste, respectivamente, as letras $w$ e e representam suas faces e a letra $P$ é centro do volume de controle.

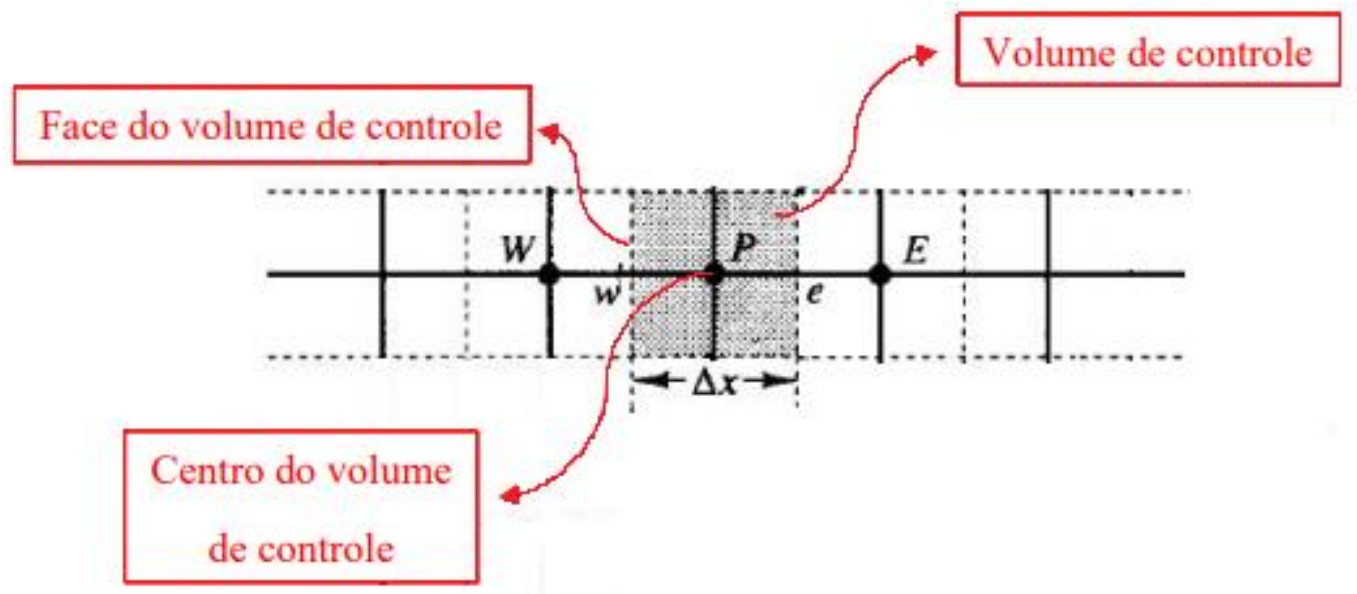

Figura 2. Ilustração da malha espacial para o Método dos Volumes Finitos.

Aplicando o método na Eq. (1), pode-se realizar a integração ao longo do tempo, em intervalos de tempo $\Delta t$ (constantes), e no espaço, de $w$ até $e$, do termo transiente (primeiro termo do lado esquerdo da referida equação), da seguinte forma:

$$
\int_{t}^{t+\Delta t} \int_{w}^{e} \frac{\partial C}{\partial t} d x d t=\Delta x\left(C_{P}^{t+\Delta t}-C_{P}^{t}\right)
$$

A integração do termo advectivo (segundo termo do lado esquerdo da Eq.(1) pode ser feita através do esquema Upwind (UDS), o qual consiste na substituição do valor da função nas interfaces $w$ e $e$ de cada volume de controle pelo valor da mesma no ponto a montante, o qual varia de acordo com o sentido da velocidade do escoamento (Versteeg; Malalasekera, 1995), ou seja:

$$
\int_{t}^{t+\Delta t} \int_{w}^{e} \frac{\partial C}{\partial t} d x d t=\Delta x\left(C_{P}^{t+\Delta t}-C_{P}^{t}\right)
$$

Para a integração do termo dispersivo longitudinal (termo do lado direito da Eq. (1) foi usada a expresão de Taylor para aproximar a derivada primeira em $x$, via diferenças centrais. Logo:

$$
\int_{t}^{t+\Delta t} \int_{w}^{e} E_{L} \frac{\partial^{2} C}{\partial x^{2}} d x d t=E_{L} \Delta t\left(\frac{C_{E}^{\theta}-2 C_{P}^{\theta}-C_{W}^{\theta}}{\Delta x}\right)
$$


Observe que o termo transiente, expresso na Eq. (4), possui as concentrações avaliadas nos instantes de tempo $t$ e $t+\Delta t$, enquanto os termos advectivo, Eq. (5) e dispersivo, Eq. (6), apresentam concentrações em função de $\theta$. Portanto, esses termos devem ser manipulados através de uma função de interpolação, dada pela Eq. (7), de forma a poder avaliar as concentrações nos mesmos instantes de tempo presentes no termo transiente, gerando assim, as formulações explícita e implícita.

$$
C^{\theta}=\theta C^{t+\Delta t}+(1-\theta) C^{t}
$$

Para a utilização da formulação explícita, toma-se $\theta=0$, ou seja, a concentração em função de $\theta$ será analisada no instante $t$. Dessa forma, obtém-se a Eq. (8):

$$
C_{P}^{t+\Delta t}=\left(\frac{U \Delta t}{\Delta x}+E_{L} \frac{\Delta t}{\Delta x^{2}}\right) C_{W}^{t}+\left(1-\frac{U \Delta t}{\Delta x}-2 E_{L} \frac{\Delta t}{\Delta x^{2}}\right) C_{P}^{t}+\left(E_{L} \frac{\Delta t}{\Delta x^{2}}\right) C_{E}^{t}
$$

Devido ao critério de estabilidade, é necessário levar em consideração a relação entre as malhas espacial e temporal, bem como a velocidade e o coeficiente de dispersão, de forma a satisfazer as desigualdades:

$$
E_{L} \frac{\Delta t}{\Delta x^{2}}<\frac{1}{2} \quad \text { ou } \quad U \frac{\Delta x}{2 E_{L}}<1
$$

Agora, adotando a formulação implícita, onde $\theta=1$ e, a concentração em função de $\theta$ é analisada no instante $t+\Delta t$, obtém-se a Eq. (9):

$$
\left(\frac{U \Delta t}{\Delta x}+E_{L} \frac{\Delta t}{\Delta x^{2}}\right) C_{W}^{t+\Delta t}+\left(1-\frac{U \Delta t}{\Delta x}-2 E_{L} \frac{\Delta t}{\Delta x^{2}}\right) C_{P}^{t+\Delta t}+\left(E_{L} \frac{\Delta t}{\Delta x^{2}}\right) C_{E}^{t+\Delta t}=C_{P}^{t}
$$

Ambas as formulações podem ser escritas através de um sistema linear e resolvidas na forma matricial, sendo a formulação explícita resolvida diretamente utilizando o produto entre matrizes e vetores e, a formulação implícita, resolvida através do método iterativo de Gauss-Seidel.

\section{RESULTADOS E DISCUSSÄO}

Tendo como enfoque validar e calibrar o modelo matemático resolvido pelo Método dos Volumes Finitos, foram realizadas diversas simulações, com a variação da malha computacional e dos parâmetros, além de ser comparados os resultados numéricos obtidos com o mesmo, com a solução analítica, dada pela Eq. (3), e os dados experimentais obtidos 
no trabalho de campo descrito em Sousa (2009), as quais tiveram com base os parâmetros das Tabelas 1 e 2. Para a implementação foi utilizado o software Scilab versão 5.5.0.

Tabela 2. Dados utilizados na simulação para a região de interesse.

\begin{tabular}{|c|c|}
\hline PARÂMETROS & VALORES \\
\hline Comprimento do trecho do rio sob análise & $500 \mathrm{~m}$ \\
\hline Tempo do experimento (tempo final) & $550 \mathrm{~s}$ \\
\hline Posição de lançamento do poluente no domínio & $100 \mathrm{~m}$ \\
\hline Posição de coleta do poluente no domínio & $200 \mathrm{~m}$ \\
\hline
\end{tabular}

\subsection{VARIAÇÃO DA MALHA ESPACIAL}

Com o intuito de determinar uma discretização espacial que possa representar, de forma coerente, a solução analítica e as concentrações obtidas experimentalmente, bem como mostrar as diferenças entre as formulações explícita e implícita, foram realizadas algumas variações na malha especial para mostrar a influência do critério de estabilidade em ambas as formulações, conforme apresentado nas Figuras 3 a 5, onde foi fixada a velocidade em $0,59 \mathrm{~m} / \mathrm{s}$, bem como o coeficiente de dispersão longitudinal em 1,82 $\mathrm{m}^{2} / \mathrm{s}$, ambos retirados de Sousa (2009). Já o intervalo de tempo da malha temporal com relação à duração do experimento, foi de $1 s$, ou seja, 550 nós.

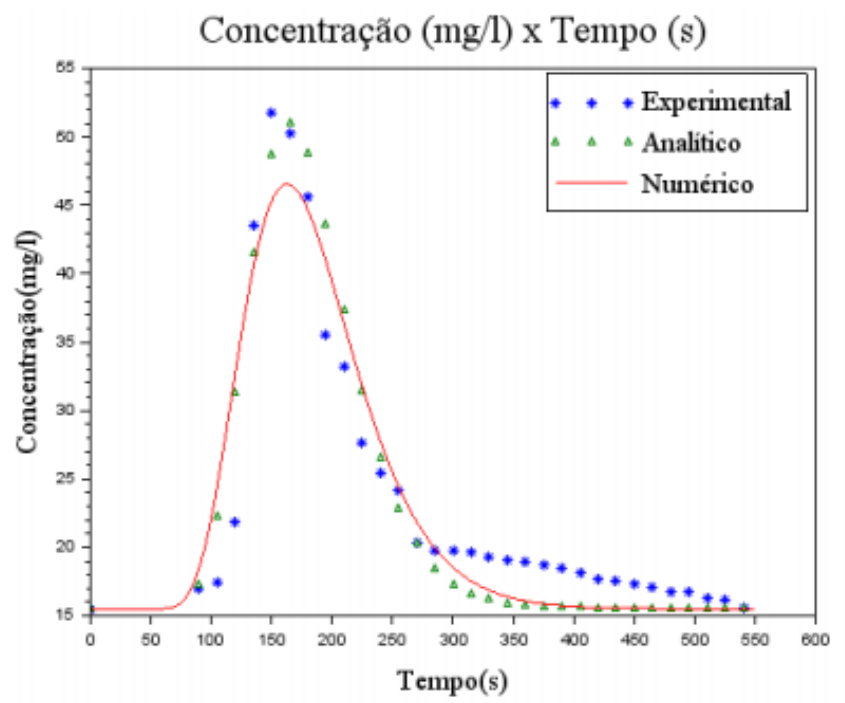

(a) Formulação Explícita.

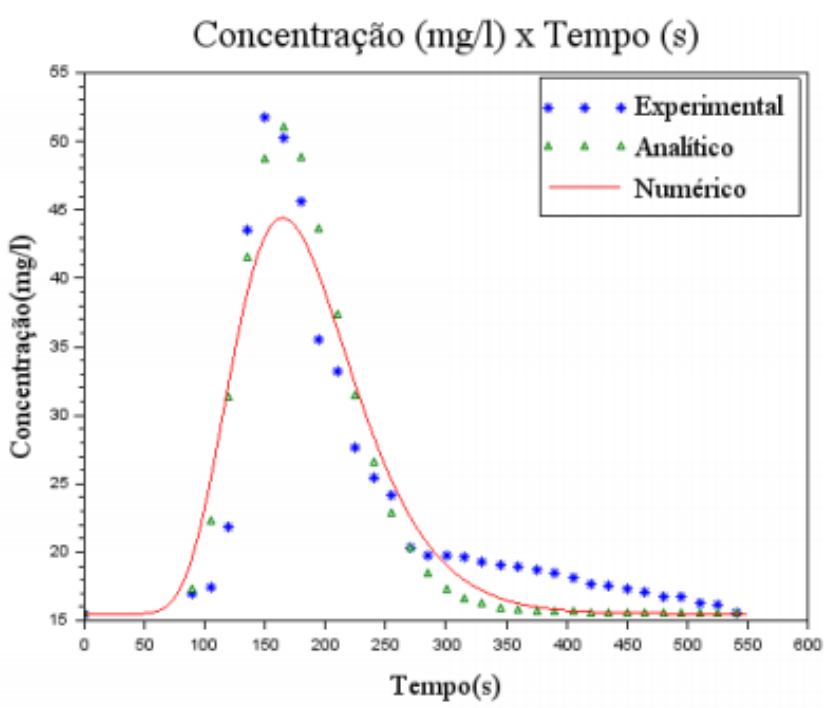

(b) Formulação Implícita.

Figura 3. Resultados obtidos considerando 200 volumes na malha espacial. 


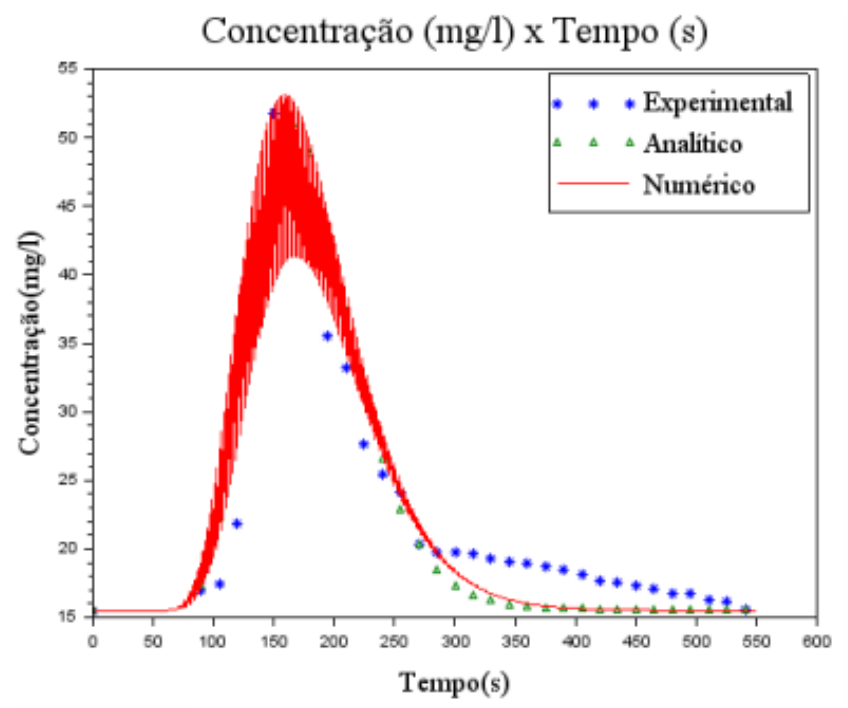

(a) Formulação Explícita.

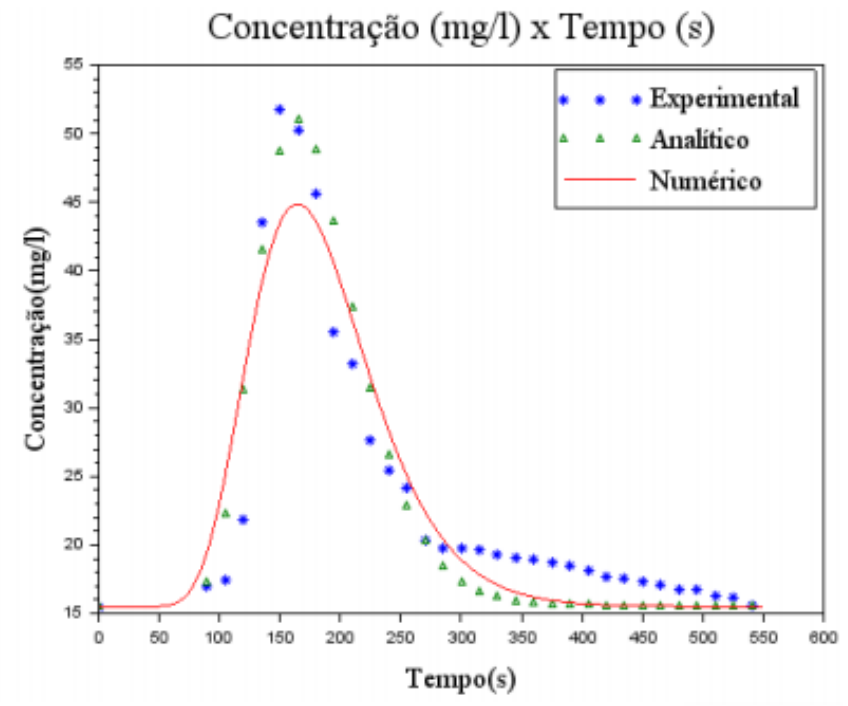

(b) Formulação Implícita.

Figura 4. Resultados obtidos considerando 225 volumes na malha espacial.

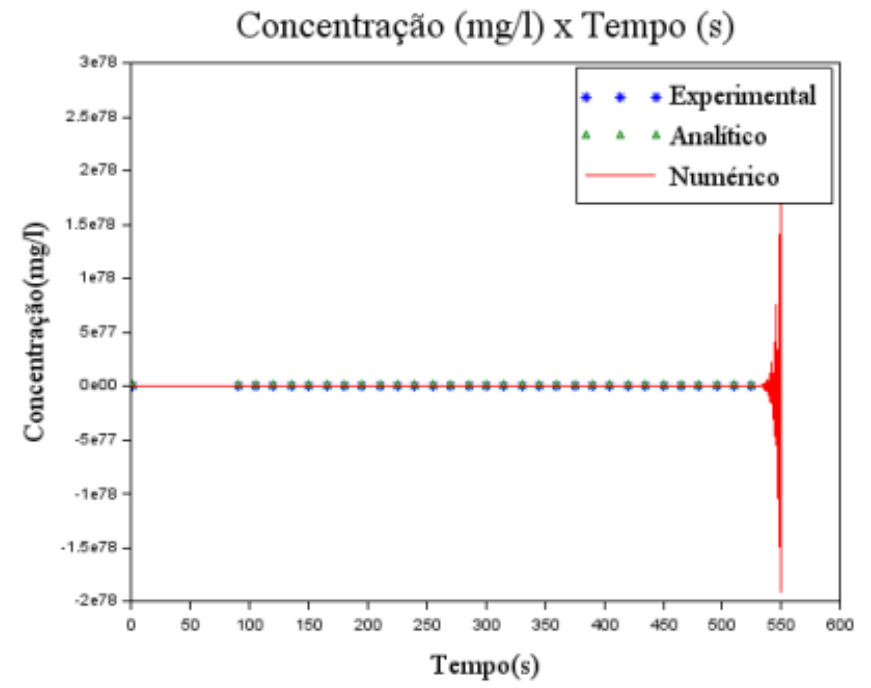

(a) Formulação Explícita.

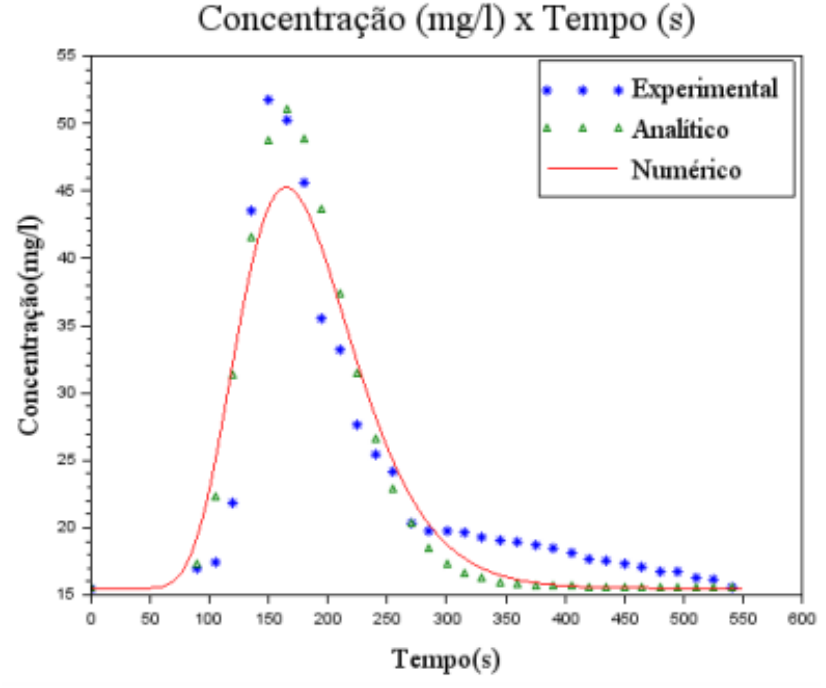

(b) Formulação Implícita.

Figura 5. Resultados obtidos considerando 250 volumes na malha espacial.

Deste modo, foi possível constatar que, para o método com formulação explícita, a partir de 225 volumes, a solução começa a apresentar inconsistência nos resultados, como mostrado na Figura 4(a) e, ao utilizar 250 volumes (Figura 5(a)), essa instabilidade se torna mais evidente, inviabilizando a visualização dos dados experimentais e solução analítica de maneira adequada.

Em seguida, foi realizado um maior refinamento da malha para a formulação implícita, onde dobrou-se a quantidade de volumes de uma simulação para a seguinte, ou seja, adotou-se 500 e 1000 volumes, cujo o intuito foi mostrar que está formulação é incondicionalmente estável, uma vez que, uma malha mais refinada não ocasiona as oscilações ocorridas na formulação explícita (Figuras 4(a) e 5(a)), conforme Figura 6. 


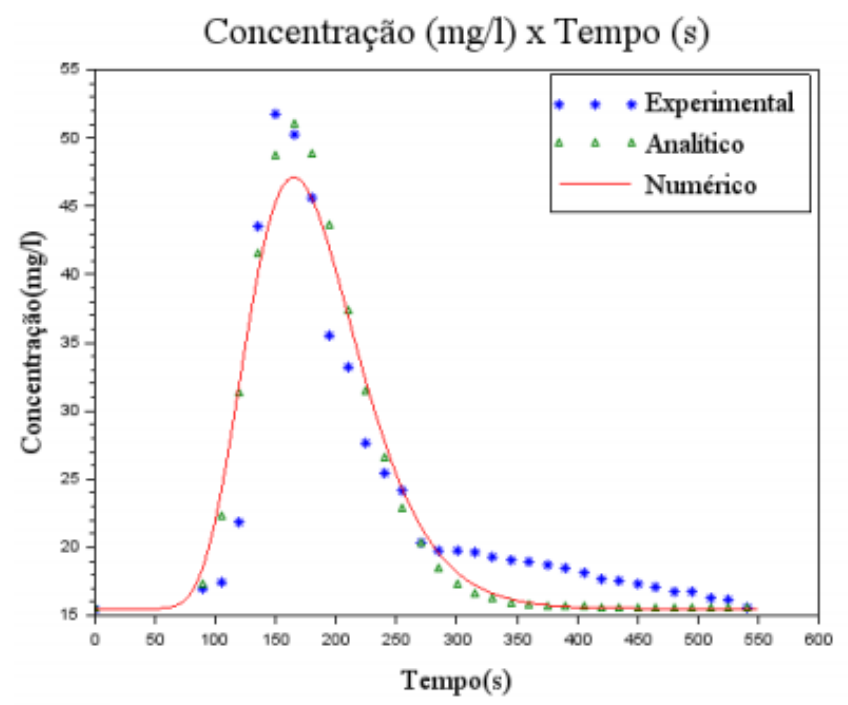

(a) 500 volumes na malha espacial.

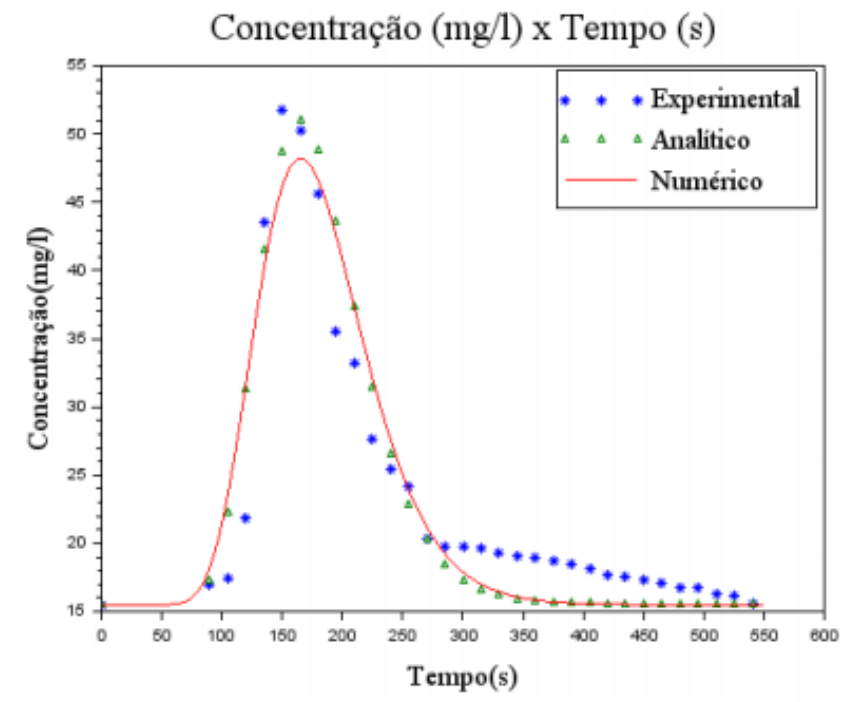

(b) 1000 volumes na malha espacial.

Figura 6. Refinamento da malha espacial para a formulação implícita.

\subsection{VARIAÇÃO DA MALHA TEMPORAL}

Posteriormente, foi feita a variação da malha temporal buscando avaliar sua influência na solução numérica, tomando como referência para ambas as formulações, os parâmetros descritos nas Tabelas 1 e 2 e fixando a velocidade em $0,59 \mathrm{~m} / \mathrm{s}$, com o coeficiente de dispersão longitudinal igual a $1,82 \mathrm{~m}^{2} / \mathrm{s}$. Com base na análise feita na seção anterior, foi adotado como 200 volumes na malha espacial, conforme as Figura 7 a 9 .

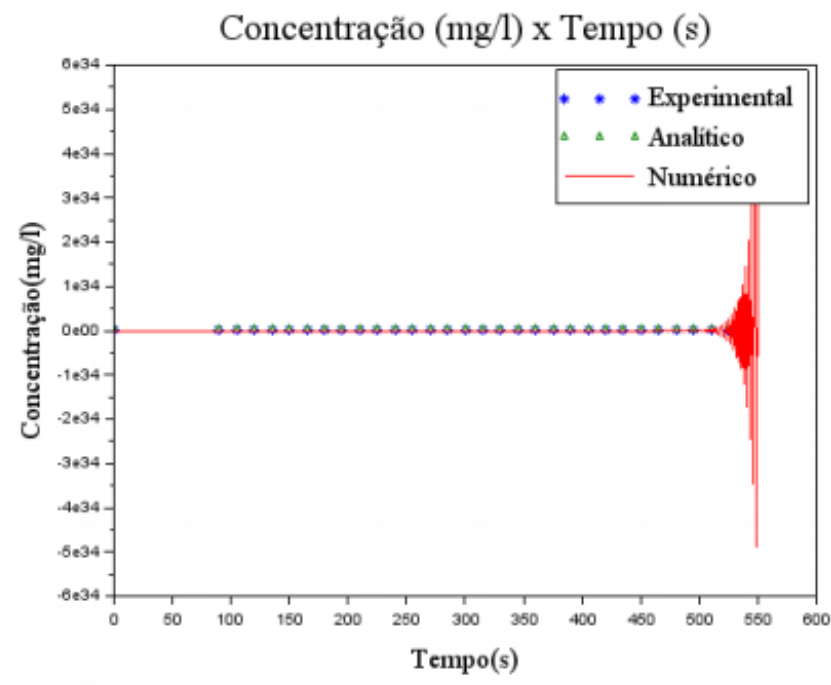

(a) Formulação Explícita.

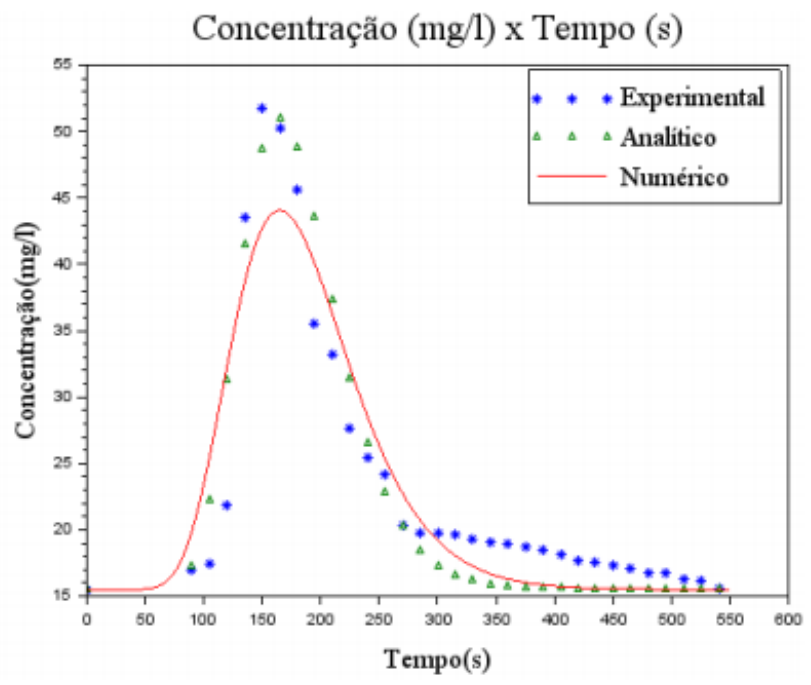

(b) Formulação Implícita.

Figura 7. Discretização da malha temporal com 400 nós. 


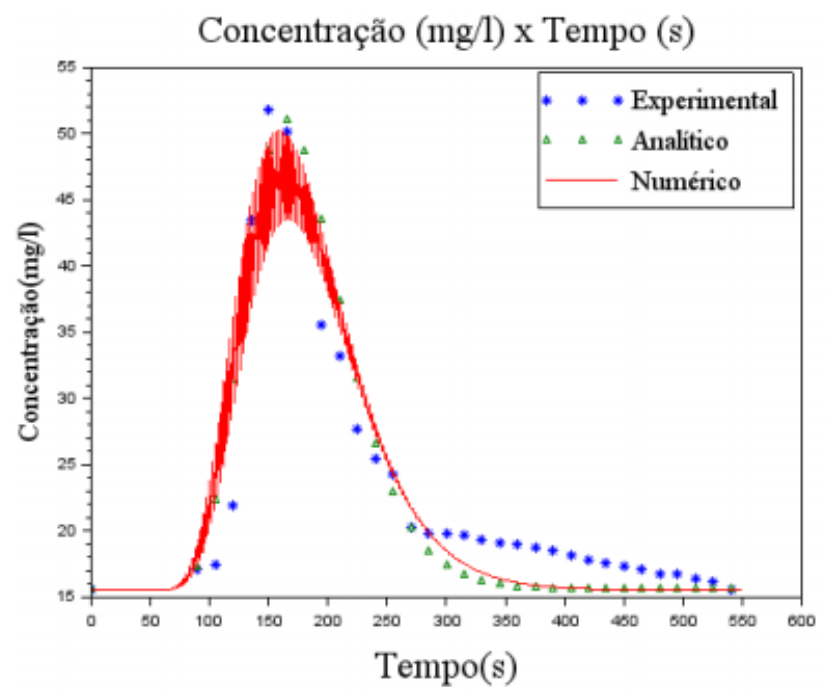

(a) Formulação Explícita.

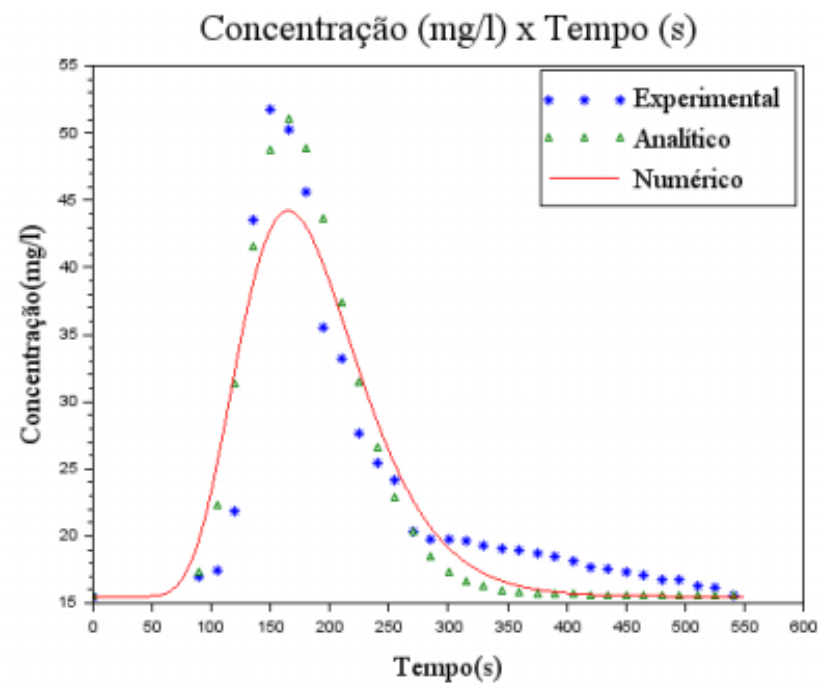

(b) Formulação Implícita.

Figura 8. Discretização da malha temporal com 450 nós.

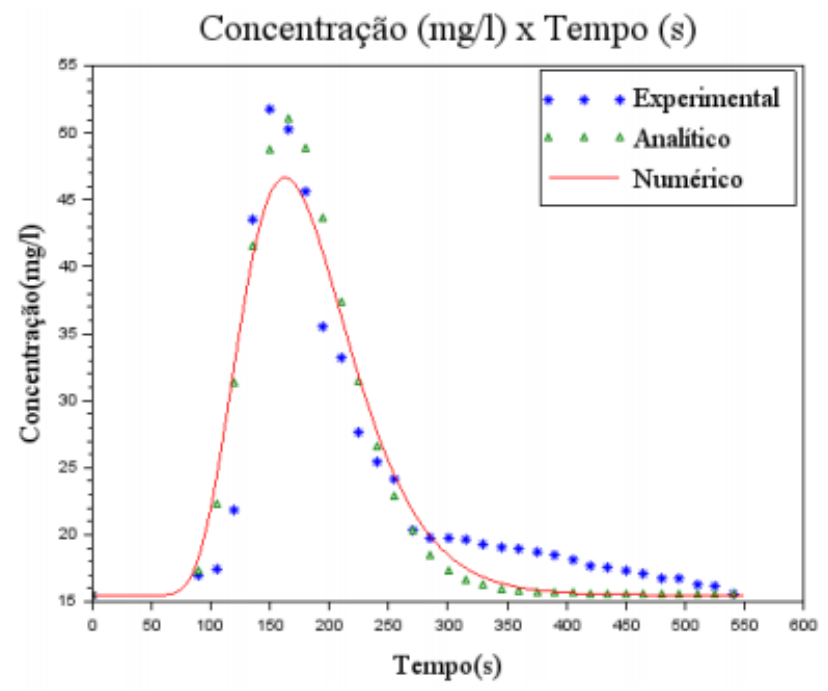

(a) Formulação Explícita.

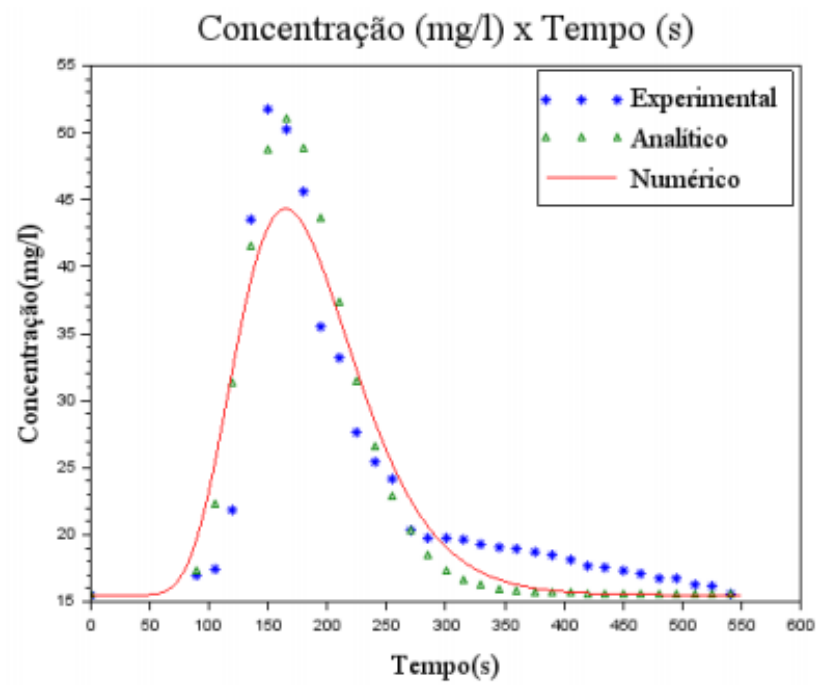

(b) Formulação Implícita.

Figura 9. Discretização da malha temporal com 500 nós.

Ao analisar os resultados obtidos com as simulações, ao tentar impor um valor inferior a 500 nós na malha temporal para a formulação explícita os resultados começam a apresentar oscilações, sendo possível visualizar com clareza na simulação para 400 e 450 nós apresentada nas Figuras 7(a) e 8(a). Em contrapartida, no método com a formulação implícita, não houve instabilidades com a redução do número de nós temporais e mostrou custo-benefício satisfatório com a discretização para 500 volumes na malha espacial.

\subsection{VARIAÇÃO DA VELOCIDADE}


Com o intuito de analisar apenas o efeito da variação da velocidade no comportamento do perfil da concentração em ambas as formulações, foram tomados valores próximos ao utilizado por Sousa (2009), ou seja, $U=0,59 \mathrm{~m} / \mathrm{s}$, e fixado o coeficiente de dispersão em $1,82 \mathrm{~m}^{2} / \mathrm{s}$. Já as malhas espacial e temporal foram definida com 200 volumes e 550 nós, respectivamente, uma vez que esta configuração não apresentou problemas de instabilidade nas Seções 3.1 e 3.2. Os resultados são apresentados nas Figuras 10 a 12.

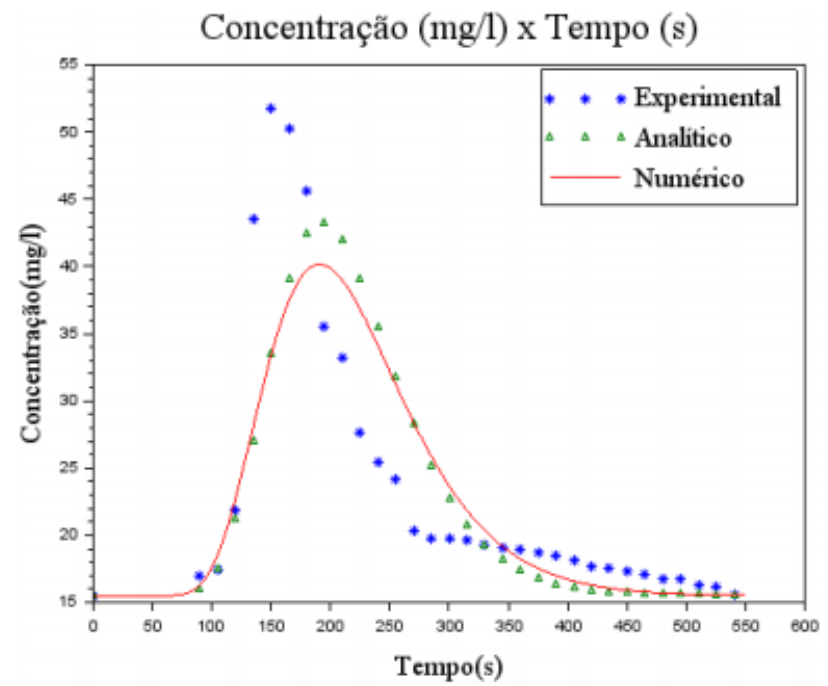

(a) Formulação Explícita.

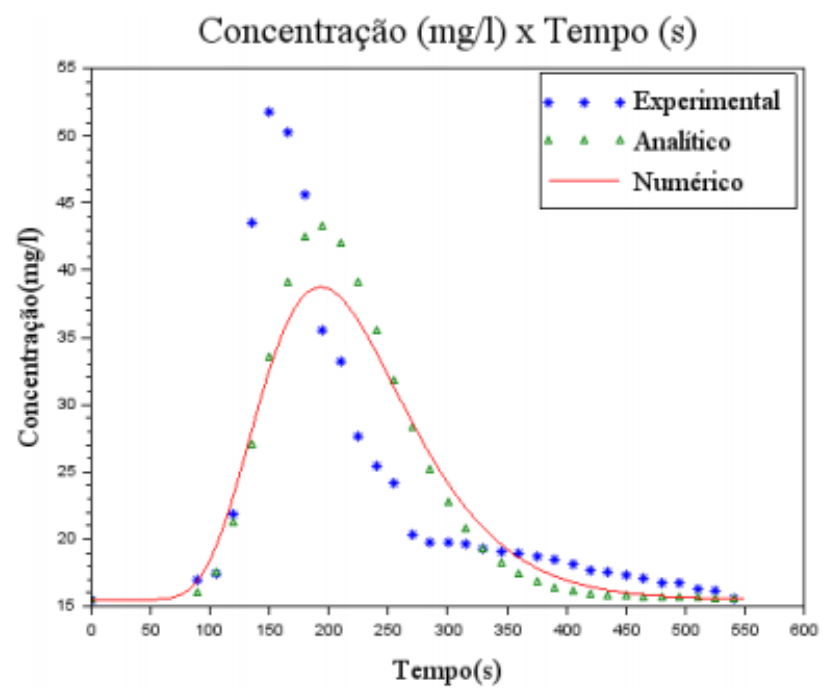

(b) Formulação Implícita.

Figura 10. Simulações para a velocidade em $0,5 \mathrm{~m} / \mathrm{s}$.

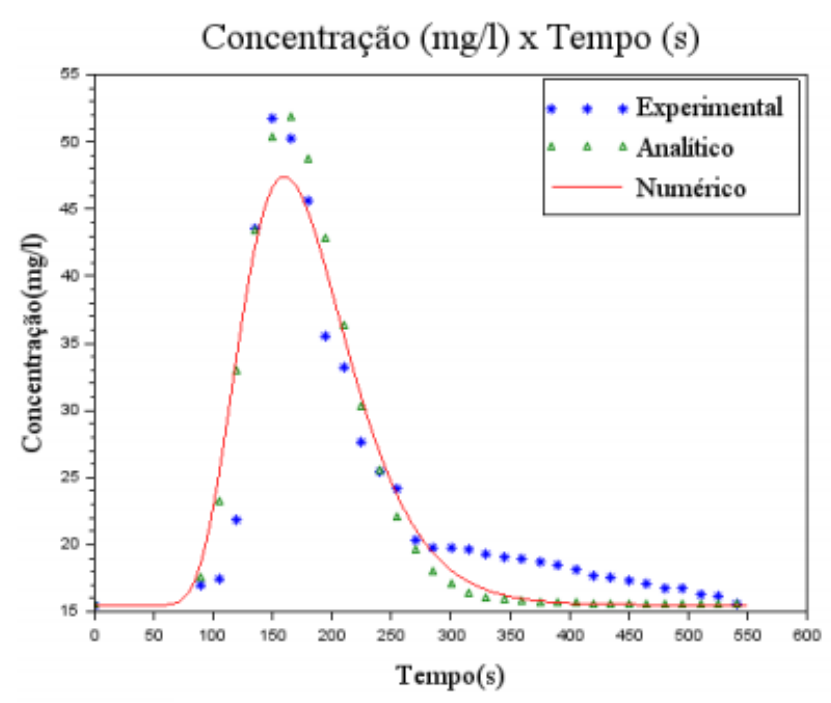

(a) Formulação Explícita.

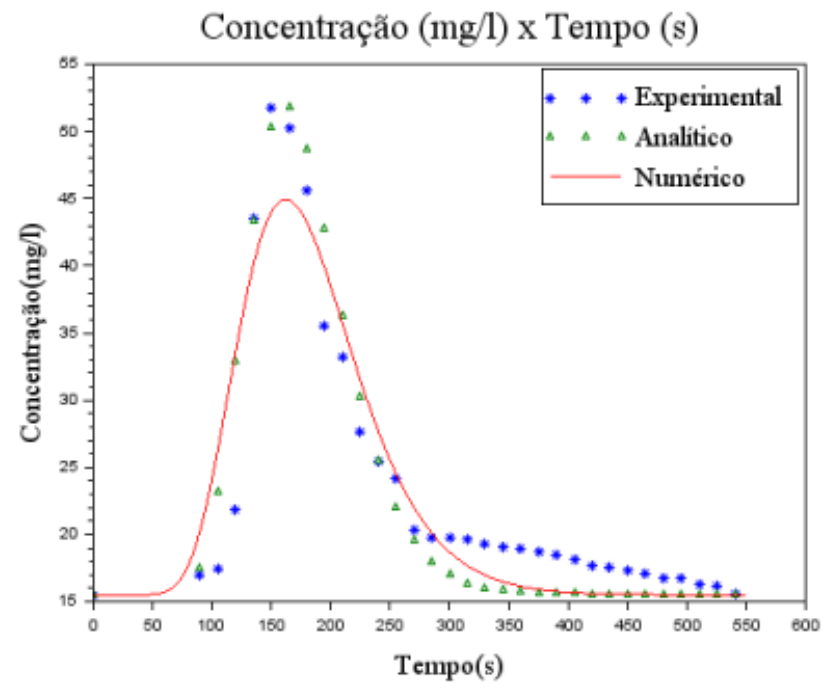

(b) Formulação Implícita.

Figura 11. Simulações para a velocidade em $0,6 \mathrm{~m} / \mathrm{s}$. 


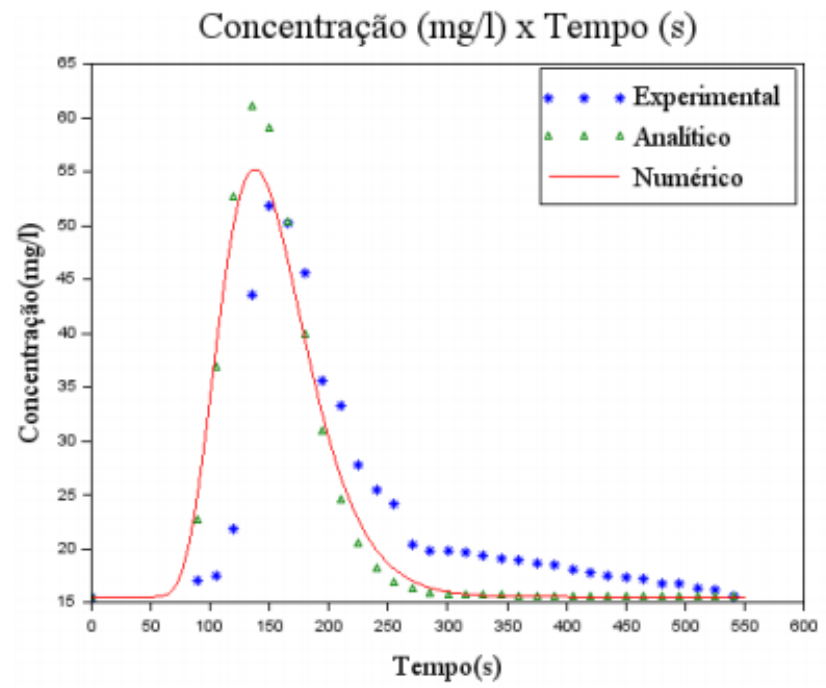

(a) Formulação Explícita.

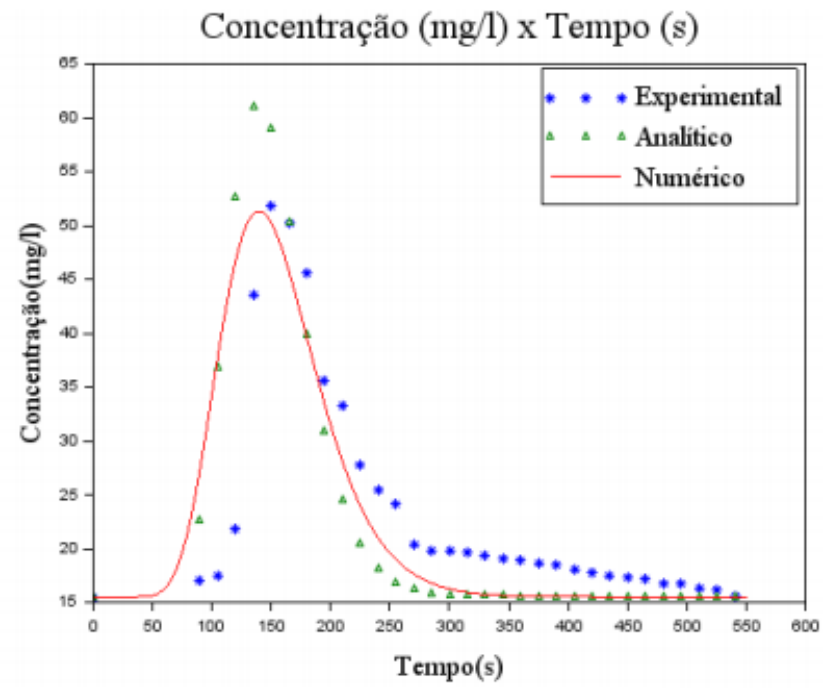

(b) Formulação Implícita.

Figura 12. Simulações para a velocidade em $0,7 \mathrm{~m} / \mathrm{s}$.

Portanto, conforme analisado ambas as formulações obtiveram uma variação para o perfil numérico da concentração similar à variação da solução analítica, o que mostra a robustez da solução numérica frente à variação deste parâmetro. Todavia as simulações com $U=0,6 \mathrm{~m} / \mathrm{s}$, apresentaram um resultado onde o pico das concentrações numéricas está alinhado aos mesmos instantes de tempo da solução analítica e dados experimentais.

\subsection{VARIAÇÃO DO COEFICIENTE DE DISPERSÃO LONGITUDINAL}

Assim como ocorrido para a análise da influência da velocidade no comportamento do contaminante, foram realizados, ainda, vários testes no que diz respeito à variação do coeficiente de dispersão longitudinal e comparados os resultados numéricos frente à solução analítica e dados experimentais. Cabe ressaltar que esse parâmetro, juntamente com a velocidade, é um dos mais críticos para a precisão das simulações geradas por esses modelos. Para isso, utilizou-se os valores de $U=0,59 \mathrm{~m} / \mathrm{s}$ e $E_{L}=1,5 \mathrm{~m}^{2} / \mathrm{s}, E_{L}=1,5 \mathrm{~m}^{2} / \mathrm{s}$ e $E_{L}=2,5 \mathrm{~m}^{2} / \mathrm{s}$, tanto para a formulação explícita, quanto implícita. Os resultados são mostrados nas Figuras 13 a 15. 


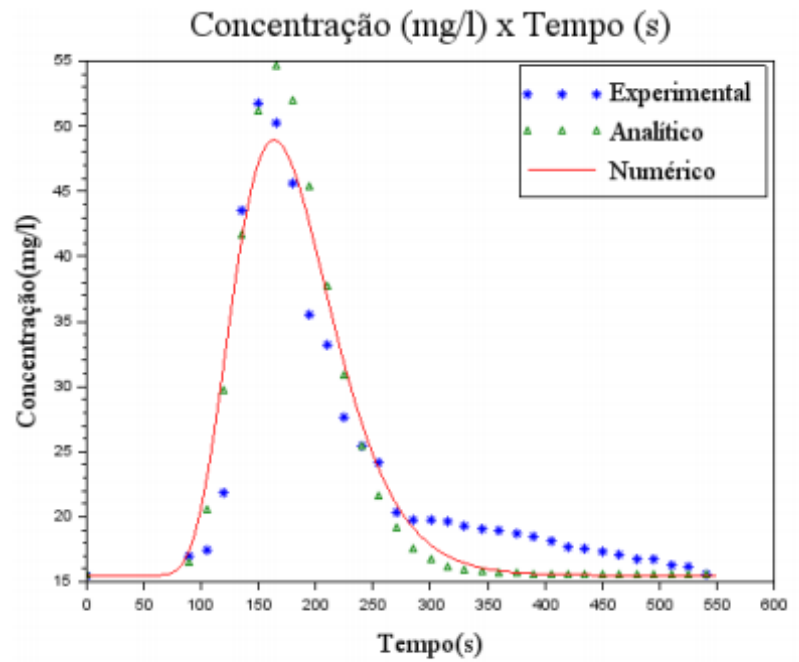

(a) Formulação Explícita.

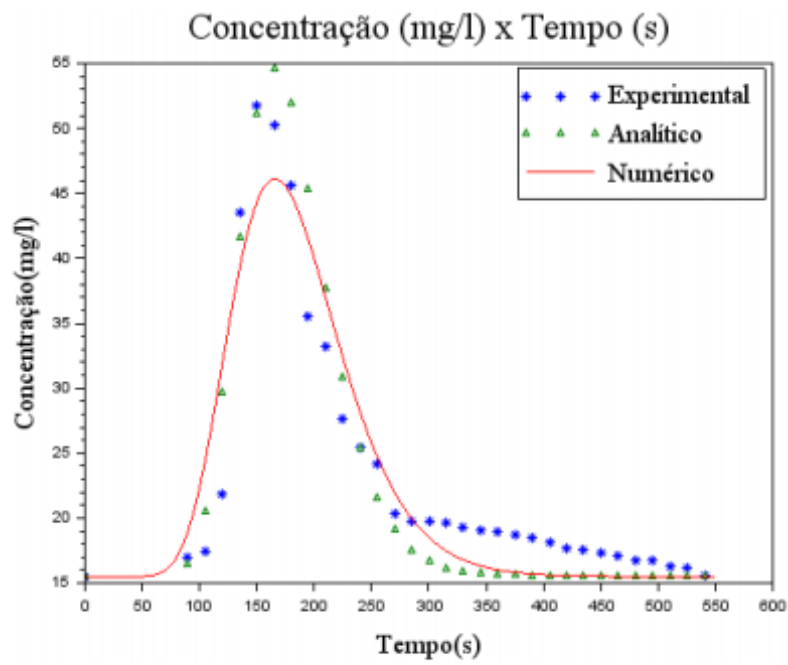

(b) Formulação Implícita.

Figura 13. Simulações para o coeficiente de dispersão longitudinal em $1,5 \mathrm{~m}^{2} / s$.

Concentração (mg/l) x Tempo (s)

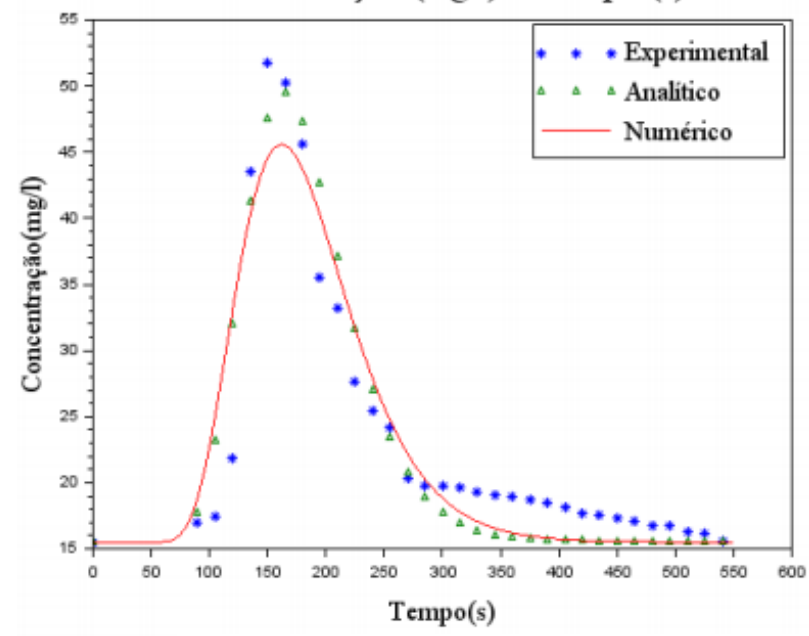

(a) Formulação Explícita.

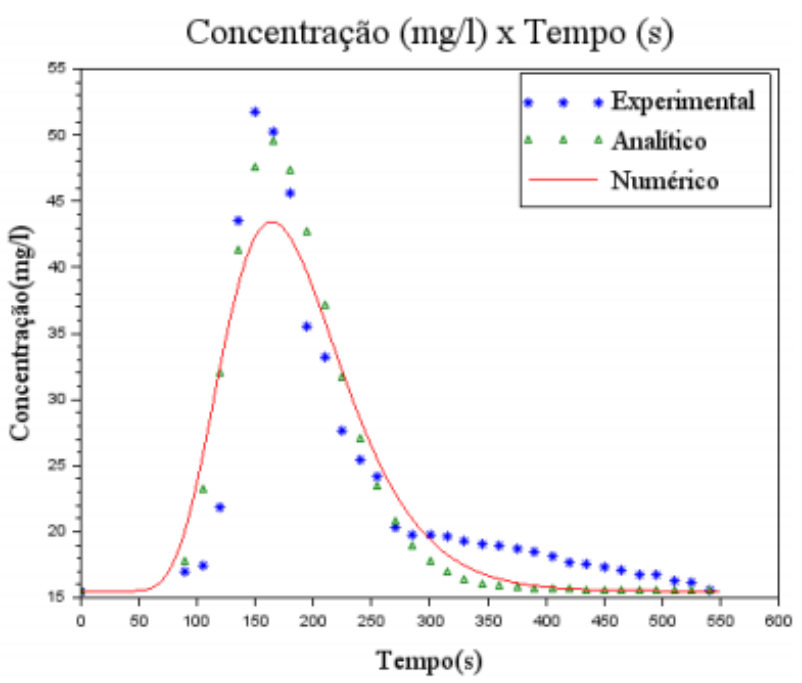

(b) Formulação Implícita.

Figura 14. Simulações para o coeficiente de dispersão longitudinal em $2,0 \mathrm{~m}^{2} / \mathrm{s}$.

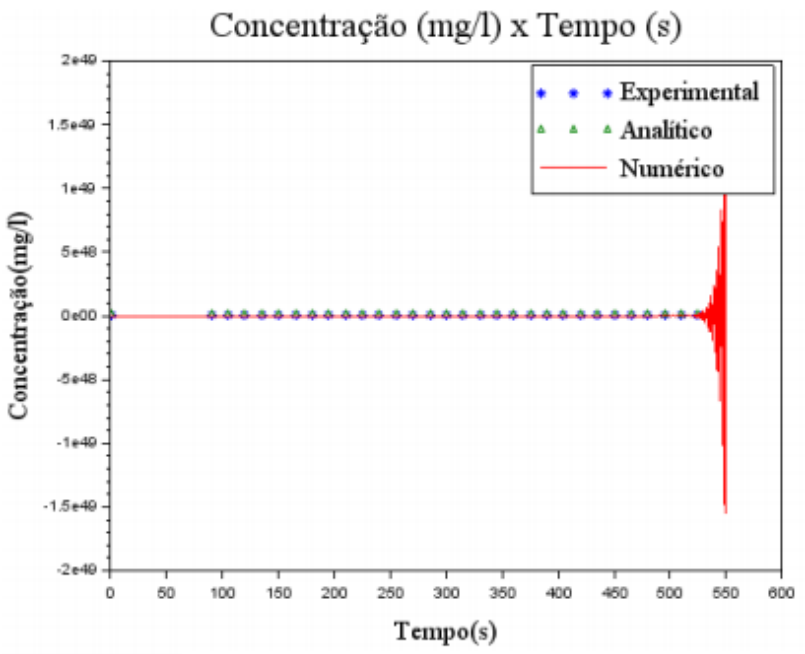

(a) Formulação Explícita.

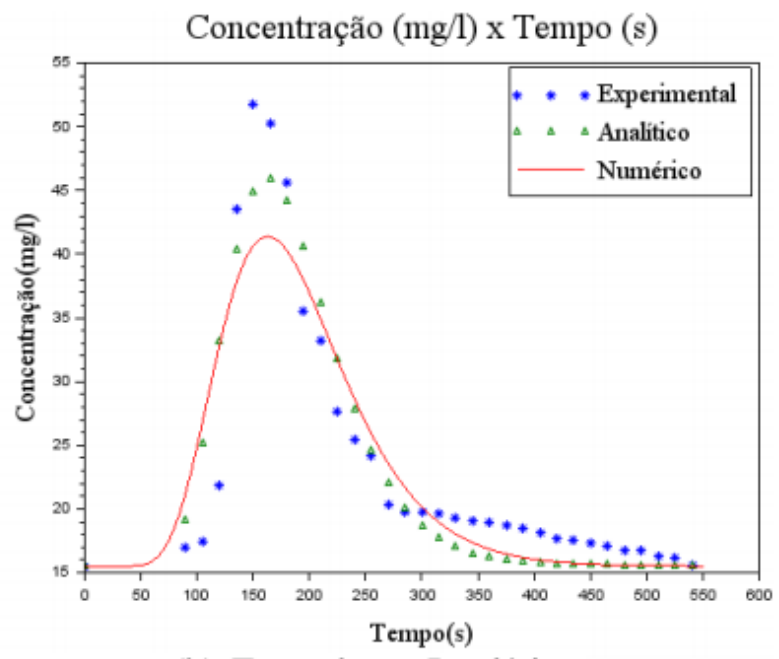

(b) Formulação Implícita.

Figura 15. Simulações para o coeficiente de dispersão longitudinal em $2,5 \mathrm{~m}^{2} / s$. 
Tendo em vista que, quanto maior o valor do coeficiente dispersivo longitudinal, maior será a diluição da pluma contaminante no mesmo sentido, foi possível constatar uma instabilidade para $E_{L}=2,5 \mathrm{~m}^{2} / \mathrm{s}$ na formulação explícita, conforme mostrado na Figura 15(a). Porém, o fato não ocorre para a formulação implícita, onde, mesmo não sendo uma simulação representativa em relação aos dados experimentais, ainda é possível observar o perfil do contaminante sem oscilações, observe a figura 15(b). Tais resultados reforçam a dificuldade em se trabalhar o ajuste de malhas e parâmetros de forma a atender o critério de estabilidade da formulação explícita.

É importante destacar que, devido ao critério de estabilidade da formulação explícita, não houve um maior refinamento da malha espacial. Para uma malha com maior número de volumes espaciais, seria necessário adotar intervalos de tempo muito pequenos para que os resultados não apresentassem oscilações, acarretando em um elevado custo computacional. Por outro lado, é possível verificar que, após o refinamento da malha para a formulação implícita, não houve uma variação significativa do pico de concentração quando se dobrou a quantidade de volumes (500 para 1000 volumes). Analisando os resultados obtidos com as formulações explícita e implícita, pode-se verificar que a formulação implícita torna-se a mais indicada no que se refere à maior flexibilidade ao se combinar a variação das malhas espacial e temporal, bem como a velocidade e o coeficiente de dispersão, uma vez que esta é incondicionalmente estável.

\section{CONSIDERAÇÕES FINAIS}

O presente trabalho teve o intuito de investigar a estabilidade da solução numérica utilizando o experimento de campo que buscou simular o transporte de contaminantes em um trecho específico do rio São Pedro, afluente do rio Macaé, onde buscou-se o ajuste mais coerente entre a solução numérica do modelo matemático dada pelo Método dos Volumes Finitos, bem como solução analítica e dados experimentais. Para sua validação, foram realizadas diversas variações das malhas espacial e temporal, velocidade e coeficiente de dispersão.

A primeira análise realizada foi a variação de malha espacial, onde foi possível constatar que a formulação explícita apresentou uma instabilidade para malhas acima de 200 volumes, já a formulação implícita se mostrou incondicionalmente estável, independente da quantidade de volumes utilizados. Ademais, ambas as formulações 
tiveram desempenho similar para 200 volumes, no entanto, uma malha mais refinada, possibilitou uma maior robustez do modelo resolvido com a formulação implícita.

Em seguida, foi analisada a variação da malha temporal, onde foi possível constatar que ambas as formulações não apresentaram variações significativas no perfil da concentração a partir de 500 nós. Nessa análise também foi possível identificar instabilidades na formulação explícita para valores inferiores a 500 nós.

Posteriormente, foram realizadas variações na velocidade de modo a obter uma análise sobre a influência desse parâmetro na concentração do contaminante, onde foi possível observar que, quanto menor a velocidade menor será o pico de concentração que chega ao ponto de coleta, bem como maior será o tempo necessário para o deslocamento do contaminante ao longo do rio.

O último parâmetro investigado nesse trabalho, foi o coeficiente de dispersão longitudinal, onde verificou-se que sua variação interfere diretamente na diluição da pluma de contaminante, sendo seu aumento ou redução inversamente proporcional à elevação do pico de concentração no ponto de coleta.

Verificou-se ainda que, após os resultados numéricos, obtidos na resolução do modelo matemático utilizando o Método dos Volumes Finitos com formulações explícita e implícita, bem como a comparação dos mesmos com a solução analítica e os dados experimentais, foi possível configurar o modelo para que as simulações por ele realizadas se comportassem de maneira satisfatória na região de interesse, sendo uma alternativa para o diagnóstico e monitoramento das águas de maneira a assemelhar-se à realidade.

No que se refere a futuros desdobramentos, o modelo em questão pode ser aplicado em corpos hídricos com características similares ou, até mesmo, ser adaptado para regiões que possuírem a geometria parecida com a que foi analisada, podendo alterar seus parâmetros a fim de calibrá-lo de acordo com cada caso específico. Ademais, sugere-se a aplicação de métodos de otimização para a estimativa dos parâmetros baseada em uma abordagem de problemas inversos de modo a estimar o valor ótimo dos mesmos.

\section{REFERÊNCIAS}

ANA - Agência Nacional de Águas. Cadernos de Recursos Hídricos. Rio de Janeiro, 2005. Disponível em: < https://www.ana.gov.br/noticias-antigas/ana-publica-a-sa-c-rie-acadernos -de-recursos.2019-03-14.1329568974>. Acesso em 10 Jan. 2020.

BACCI, D. C.; PATACA; E. M. Educação para a água: Estudos avançados, v. 22, n. 63, p. 211-226, 2008. Disponível em: <http://www.periodicos.usp.br/eav/article/vi ew/10302/ 11957>. Acesso em: 08 Jan 2020. 
CONAMA - Conselho Nacional do Meio Ambiente. Resolução CONAMA № 430, de 13 de maio de 2011. Disponível em: <http://www2.mma.gov.br/port/conama/legiabre.cfm? codlegi=646>. Acesso em: 12 Jan. 2020.

CONAMA - Conselho Nacional do Meio Ambiente. Resolução CONAMA № 467, de 16 de junho de 2015. Disponível em: <http://www2.mma.gov.br/port/conama/legiabre.cfm? codlegi=712>. Acesso em: 12 Jan. 2020.

FRANCISCO, L. V. Tales de Mileto: Tudo Começa na Água. Disponível em: <https://brasil escola.uol.com.br/losoa/tales-mileto.htm.>. Acesso em: 28 Jan. 2020.

FREITAS, L. E.; NUNES, F. S. B.; CRUZ, J. C. H. O.; VILELA, C.; MENDES, S., Silva, A. C. S.; BORGES, G. Atlas Ambiental da Bacia Hidrográfica do Rio Macaé. $1^{\circ}$ ed. Rio de Janeiro: Editora Nova Tríade do Brasil Ltda, 2015.

ONU - Nações Unidas. A ONU e a água. 2010. Disponível em: <https://nacoesunidas.org /acao/agua/> Acesso em: 10 Fev. 2020.

ONU - Nações Unidas. ONU defende soluções para problemas hídricos baseadas na natureza. Disponível em: <https://nacoesunidas.org/em-dia-mundial-da-agua-onu-defende -solucoes-para-problemas-hidricos-baseadas-na-natureza/>. Acesso em: 08 Jan. 2020.

SOUSA, E. P. Avaliação de Mecanismos Dispersivos em Rios Através de Problemas Inversos. Dissertação (Mestrado em Modelagem Computacional), Instituto Politécnico, Universidade do Estado do Rio de Janeiro, Nova Friburgo, RJ, 2009.

VERSTEEG, H. K.; MALALASEKERA W. An introduction to Computational Fluid Dynamics: The Finite Volume Method. Longman Scientific Technical: England, 1995. 